\title{
Opioids in the immune system: from experimental studies to clinical practice
}

\author{
Jairo Moyano \\ Luisa Aguirre
}

1. Anesthesia Department, Pain Service, Hospital Universitario Fundación Santafé de Bogotá, Bogotá, Colombia

http://dx.doi.org/10.1590/1806-9282.65.2.262

\begin{abstract}
SUMMARY
INTRODUCTION: Opioids interact with both innate and adaptive immune systems and have direct effects on opioid receptors located on immune cells. Research on this topic has provided evidence of the opioid influence on the immune response associated with surgical stress. The immunological effects of opioids are currently being investigated, particularly whether they influence the outcome of surgery or the underlying disease regarding important aspects like infection or cancer progression. This review addresses background research related to the influence of the opioid receptor on the immune system, the immunosuppressive effect associated with major opioids during the perioperative period, and their clinical relevance. The objective of the study was to review the effects of opioids on the immune system. Methods: A search strategy was conducted in PubMed, Embase, and the Cochrane databases using the terms "immunosuppression," "immune system," "surgical procedures," "analgesics," "opioids" and "perioperative care." Results: The immunosuppressive effect of opioids was identified over 30 years ago. They include signaling and acting directly through immune cells, including B and T lymphocytes, NK cells, monocytes, and macrophages, as well as activating the downstream pathways of the hypothalamic-pituitary-adrenal (HPA) axis leading to the production of immunosuppressive glucocorticoids in the peripheral and sympathetic nervous system.
\end{abstract}

KEYWORDS: Immunosuppression. Immune system. Surgical procedures, operative. Analgesics. Analgesics, opioid.

\section{INTRODUCTION}

Millions of people undergo surgical procedures under general anesthesia or sedation annually, many of whom are immunosuppressed patients, such as elderly, oncology, or immunomodulatory therapy patients. According to the distribution of the population pyramid, these groups of individuals are expected to increase. $^{1}$

Opioids are necessary substances used medically for pain management and anesthesia during the perioperative period for any major surgery. ${ }^{2}$ The effect of opioids on the immune system has become a research field of great interest, given that opioid use could be related to a poor surgical outcome or a variety of disease processes, such as infection or cancer. ${ }^{3}$

A significant inflammatory response characterizes the perioperative period of major surgery. Immunosuppression accompanies this secondary to the interaction of several factors, such as surgical stress, anesthetics, analgesics, hypothermia, lung ventilation, and the patient's underlying disease. ${ }^{4}$

Several studies have demonstrated that opioids influence the immune system by altering the migration and functional activity of innate immune responders, creating a compromising environment

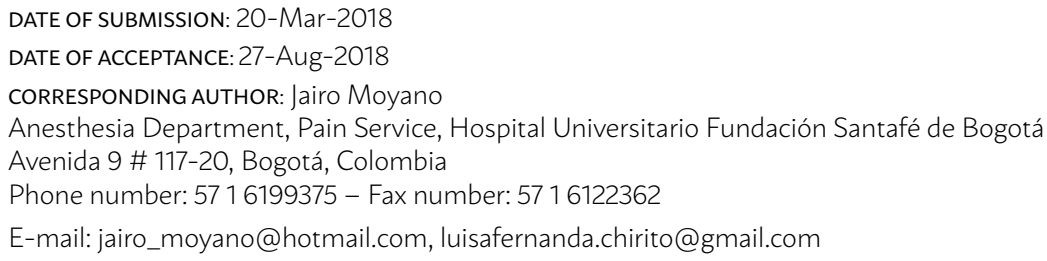


that is detrimental to the host's ability to eradicate pathogens (Fig 1). ${ }^{5}$ Morphine may decrease the effectiveness of both natural and adaptive immunity and significantly reduce cellular immunity (Table 1). ${ }^{6}$ Furthermore, morphine treatment has been associated with increased morbidity and mortality due to the development of infection and accelerated cancer progression in animal models. ${ }^{6}$ Additionally, some studies suggest that opioids that are widely used in clinical practice and during the perioperative period, such as morphine, fentanyl, and remifentanil, may worsen the immunosuppressive effect of surgery. ${ }^{7-9}$

The primary objective of this review is to discuss the clinical impact that opioids have on the immune system during the perioperative period considering the current academic literature. In addition, we review the expression of opioid receptors in the immune system, the immunosuppressive effect of surgical stress and the investigations related to this field in humans.

\section{METHODS}

A literature search of indexed scientific articles was conducted in MEDLINE and EMBASE using Medical Subject Heading (MeSH) and DeCS keywords in English. The English keywords included "immunosuppression”, "immune system”, "surgical procedures", "analgesics", “opioids” and "perioperative care". Articles that reported findings of opioids such as fentanyl, morphine, remifentanil, and tramadol were included. Given the paucity of literature including humans, all papers found in the literature were reviewed.

TABLE 1. INNATE VERSUS ADAPTIVE IMMUNITY

\begin{tabular}{l|l|l} 
Features & Primitive and broad & $\begin{array}{l}\text { Highly specific (T and } \\
\text { B cell reports) }\end{array}$ \\
\hline Speed of onset & Immediate & Approx. 3-day lag \\
\hline Regulation & $+/-$ & ++++ \\
\hline Potency & Lower & Higher \\
\hline Kinetics & Fast (hours-days) & Slow (days-wks.) \\
\hline Amplification & No (insignificant) & Yes \\
\hline Duration & Short (days) & Long (months/yrs.) \\
\hline Memory & No & Yes \\
\hline Activity & Always present & Normally silent \\
\hline Specificity & Unspecific & Highly specific \\
\hline
\end{tabular}

\section{Results}

\section{Expression of opioid receptors in immune} cells and their immunomodulatory effect

Opioid receptors belong to the family of transmembrane G protein-coupled receptors (GPCR). Four classical opioid receptors have been identified, and ORL-1 (nociceptin/orphanin FQ receptor). Furthermore, there is pharmacological evidence that suggests the presence of subtypes and variants of opioid receptors. ${ }^{10}$

The immunosuppressive effect of opioids was identified over 30 years ago when Wybran et al."11 first reported the presence of opioid receptors in normal human $\mathrm{T}$ lymphocytes. Subsequent studies documented that endogenous and exogenous opioids not only induce analgesic effects by regulating preand post-synaptic sensory neurons but also interact with peripheral opioid receptors present in the immune system, resulting in other biological effects including immunomodulation. ${ }^{5}$

Opioid peptides are found in many leucocyte subpopulations including lymphocytes, monocytes, and granulocytes in the peripheral blood and lymph nodes, and also at the site of experimentally induced or clinical inflammation. ${ }^{12}$ In peripheral inflamed tissue, opioid peptides including endorphin, (met)-enkephalin, dynorphin A, and endomorphin are produced by leukocytes and released in response to a stimulus, leading to an antinociceptive effect. ${ }^{13}$ the blocking of endorphin activity, achieved by either administration of opioid antagonists (naloxone and naltrexone) or immunoglobulins, was reported to increase natural killer (NK) cell activity and lymphoproliferation within minutes. These observations indicate that removing the effect of the opioid by way of an antagonist or an antibody can affect specific immune responses, suggesting that there is an endogenous opioidergic effect on some immune functions. ${ }^{14}$ As endorphins play a role in modulation of the immune response, inhibition of endorphins should theoretically lead to Th1-type immune responses, while increases in endorphins should lead to Th2-type immune responses. ${ }^{3,15}$

The interactions between opioid receptors and several molecules involved in the immune response are complex and multifactorial ${ }^{3}$. Endogenous opioid peptides play an immunomodulatory role; however, the effect of exogenous opioids can extend to the physiological control of the immune system, which has an important impact on immune responses. ${ }^{3}$ Endog- 


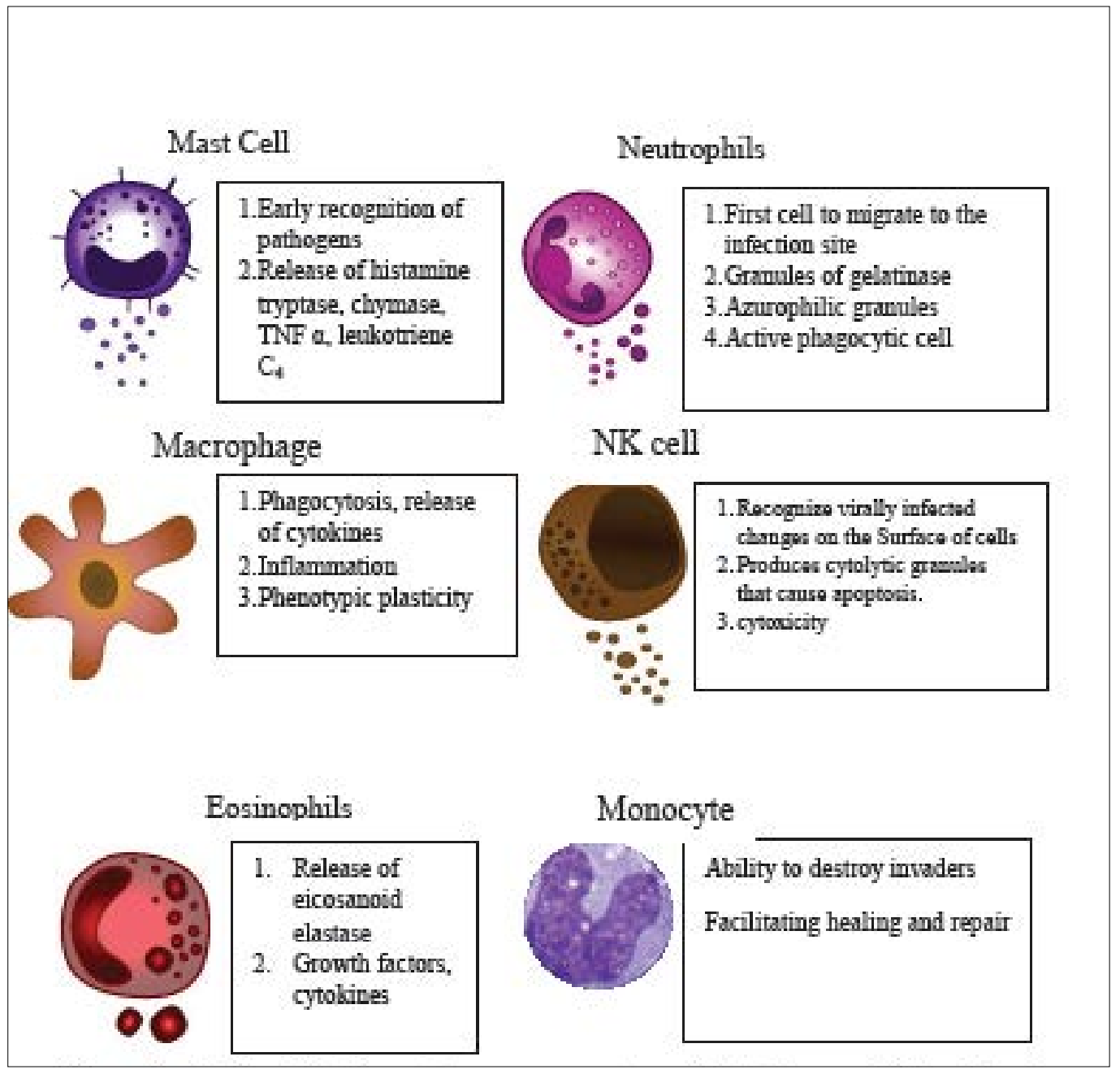

FIGURE 1. CELLS OF THE INNATE IMMUNE SYSTEM AFFECTED BY APIOID ANALGESICS

enous opioids modulate the immune system, while exogenous opioids mediate immunosuppression.$^{16,17}$

The immunosuppressive effects of opioids have been observed in several different models. These effects include signaling and acting directly through immune cells including B and T lymphocytes, NK cells, monocytes, and macrophages, as well as activating the downstream pathways of the hypothalamic-pituitary-adrenal (HPA) axis leading to the production of immunosuppressive glucocorticoids in the peripheral ${ }^{5,6}$ and sympathetic nervous system, causing the release of noradrenaline. Both glucocorticoids and noradrenalin negatively modulate the immune system. ${ }^{6,18}$

\section{PERIOPERATIVE PERIOD}

\section{Surgical stress and immune suppression}

The perioperative period of any major surgery is characterized by an inflammatory response accompa- nied by immune suppression resulting from the interaction of several factors including surgical stress, anesthetics, analgesics, hypothermia, lung ventilation, and the patient's underlying disease. ${ }^{4,19}$ In addition, tissue injury secondary to a surgical lesion can cause changes in metabolic function and defense mechanisms in the patient, leading to an increase in catabolism, immunosuppression, and postoperative morbidity. Thus, the type of anesthetic and surgical technique should be modified to control this response, especially in major surgeries in which it can cause the most harm and increase patient morbidity. ${ }^{20}$

Opioids are essential drugs that provide the analgesic component of general anesthesia as well as controling the neurovegetative response to surgical trauma. ${ }^{2}$ Their ability to reduce the stress response is related to the modulation of nociception in different sites of the neuraxis. Also, they can influence the neuroendocrine response in the central nervous system and act as potent inhibitors of the HPA axis. ${ }^{2}$ 


\section{Opioids administered during the perioperative period}

The classic opioid receptors, where the opioids act, are distributed widely throughout the central nervous system and throughout the periphery, occupying sites within the vas deferens, knee joint, gastrointestinal tract, heart, and immune system, amongst others. Opioid receptors have a series of endogenous ligands including endorphins, (met)-enkephalin, leu-enkephalin, dynorphin (A and B) and endomorphins (1 and 2). ${ }^{21}$

Opioids are widely prescribed during the perioperative period to block autonomic responses related to surgical trauma and acute postoperative pain control. ${ }^{22}$ Almost all patients undergoing major surgery have uncontrolled postoperative pain even if they receive non-opioid analgesics. Consequently, opioids are a principal component of postoperative analgesia in patients undergoing major surgery. ${ }^{23}$

In this paper, we analyze the research available on opioids that are frequently used during the perioperative period including fentanyl, remifentanil, morphine, and tramadol.

\section{Fentanyl}

Fentanyl is a $\mu$-opioid agonist which is widely used in clinical practice for analgesia, sedation, and anesthesia. ${ }^{24}$ High doses suppress the associated response to surgery stress. Furthermore, it has a fast mechanism of action because it is highly lipid-soluble. Recovery depends on several factors including dosage, time of infusion and the number of doses administered..$^{24}$ It is metabolized to a non-toxic metabolite, and its renal clearance is less than $10 \%$, making fentanyl a drug that is safe to use in patients with renal and hepatic impairment. However, it should be administered with caution in continuous infusions. ${ }^{25,26}$

An in vitro study evaluated the effect of fentanyl on natural killer cell cytotoxicity (NKCC) in 40 different patients who were exposed to either a high (75$100 \mu \mathrm{g} / \mathrm{kg})$ or low $(1-5 \mu \mathrm{g} / \mathrm{kg})$ dose of the drug during the perioperative period. ${ }^{8}$ This study found that both doses had the same effect on NKCC on the first postoperative day; however, patients exposed to the low dosage showed faster recovery of NKCC suppression, while patients given the higher doses of fentanyl still showed suppression 48 hours after surgery. ${ }^{8}$

Similar findings were reported in a study by Yardeni et al. ${ }^{27}$ who investigated the ex vivo effects of high, intermediate, and low doses of fentanyl on immune function during the postoperative period of 60 patients. Secretion of the proinflammatory cytokines IL-1 and IL-6 were significantly diminished in patients treated with the high and intermediate doses of fentanyl when compared with the low dose. However, similar suppression of NKCC and IL-2 secretion was observed among the three groups ${ }^{27}$

Yeager et al..$^{28}$ administered fentanyl to seven healthy volunteers at an initial dose of $3 \mu \mathrm{g} / \mathrm{kg}$ followed by an infusion of $1.2 \mu \mathrm{g} / \mathrm{kg} / \mathrm{h}$ for 2 hours to evaluate the effects on innate and acquired immunity in humans and on leukocyte subpopulations in peripheral blood. This short-term exposure to fentanyl produced a significant increase in circulating CD16+ and CD8+ lymphocytes. Likewise, they reported elevated NKCC. This was due to an increase in the population of NK cells, not to an increase in activity. There was no significant effect in any other immunological parameter. ${ }^{28}$

Jacobs et al. ${ }^{29}$ treated seven healthy individuals intravenously with fentanyl at a dose commonly applied to induce or balance anesthesia $(0.2 \mu \mathrm{g} / \mathrm{kg})$, with five subjects treated with saline as a placebo. There was an increase in NK cell numbers (CD16+/CD56+); however, pretreatment with naloxone prevented the fentanyl-induced NK cell increase in approximately half of the individuals.

Contradictory results have been reported in studies. However, it is important to note the insufficient number of patients and the low doses used in these studies.

\section{Remifentanil}

Remifentanil is an ultra-short-acting $\mu$-opioid agonist. It is used in general anesthesia and has the capacity to rapidly suppress the autonomic, hemodynamic, and somatic responses to a noxious stimulus. ${ }^{2}$ This drug has a unique ester structure that allows it to be hydrolyzed by blood esterases, thus resulting in fast-acting metabolism and a rapid reduction in serum concentrations of the drug after interruption of the infusion. ${ }^{2}$

Remifentanil has several clinical advantages when compared with other opioids, one of which is that organ dysfunction does not alter the pharmacokinetics of remifentanil, which has been proven for renal and hepatic impairment. Although its primary metabolite is excreted through the kidney, it has only $1 / 300$ to $1 / 4600$ of the activity of remifentanil ${ }^{30}$. These properties have led to the extensive use of 
remifentanil for general anesthesia and sedation in a variety of patients and clinical scenarios. ${ }^{30-33}$

The current literature related to the specific effects of remifentanil on the immune system is limited. Sacerdote et al. ${ }^{34}$ evaluated the effects of remifentanil on the immune system of rats and identified early suppression of the immune response caused by a significant reduction in the activity of NK cells and proliferation of lymphocytes without any change in leukocyte number. A study performed by Cronin et al. ${ }^{35}$ assessed the effects of a low-dose (0.02-0.04 $\mu \mathrm{g} /$ $\mathrm{kg} / \mathrm{min}$ ) remifentanil infusion on NK cells in healthy volunteers, concluding that there was no alteration in the number nor the cytolytic function of these cells after an 8-hour infusion.

Cytokines such as TNF- $\alpha$, IL- 6 , and IL- 8 are important mediators of the immune response. The human neutrophil activation induced by lipopolysaccharides occurs because of the activation of mitogen-activated protein kinases (MAPKs) to produce cytokines activated by lipopolysaccharides. ${ }^{3}$ Unlike other opioids, remifentanil attenuates the activation of human neutrophils exposed to lipopolysaccharides, reducing intracellular signaling pathways such as p38 and extracellular signal-regulated protein kinases 1 and 2 (ERK1/2). Furthermore, there is decreased expression of proinflammatory cytokines including TNF- $\alpha$, IL- 6 , and IL- 8 in a dose-dependent fashion. ${ }^{36}$ The effect of decreased activation of cytokines and MAPKs has been reported to be reversed with a kappa-opioid receptor antagonist. ${ }^{36}$

The effects of clinically relevant concentrations of remifentanil on polymorphonuclear neutrophil migration through endothelial cell monolayers (ECM) has been assessed, with dose-dependent inhibition reported. ${ }^{37}$ Large concentrations of this drug lead to a significant reduction in neutrophil migration through ECM. The main effect of remifentanil on endothelial cell adhesion is reduced expression of endothelial cell adhesion molecules; however, this inhibitory effect is weaker than that of fentanyl. ${ }^{37} \mathrm{In}$ a study of a prospective cohort of 235 patients, Inagi et al. ${ }^{9}$ found that remifentanil-based anesthesia increased the incidence of surgical site infection after colorectal surgery and transiently altered the number of leukocytes and neutrophils.

\section{Morphine}

Morphine has been widely studied and is commonly considered to be the archetypal opioid anal- gesic and the agent to which all other painkillers are compared. ${ }^{21}$ It has been well characterized in both clinical and preclinical studies, and decreases in several functions of both natural and adaptive immunity have been reported, with a significant reduction in cellular immunity after acute and chronic administration of morphine. ${ }^{6}$

In general, the effects of in vivo administration of morphine are associated with a reduction in innate immunity, mainly macrophages, and monocytes, with inhibition of proliferation and differentiation induced by macrophage colony-stimulating factor. ${ }^{14}$

The literature points to the clear conclusion that in vivo administration of morphine suppresses the function of NK cells, T cells, B cells, and polymorphonuclear leukocytes. ${ }^{17}$ In 1996 , Yeager et al. ${ }^{38}$ conducted a clinical study to evaluate the in vivo effects of morphine on human immunity. Participants were healthy volunteers who received continuous intravenous exposure to morphine for 24 hours. The study was conducted in two sequential phases. During the first phase, participants received a low dose of morphine (loading dose of $0.025 \mathrm{mg} / \mathrm{kg}$ and infusion of $0.015 \mathrm{mg} / \mathrm{kg} / \mathrm{h}$ ) or high dose of morphine (loading dose of $0.05 \mathrm{mg} / \mathrm{kg}$ and infusion of $0.03 \mathrm{mg} / \mathrm{kg} / \mathrm{h}$ ). Peripheral blood for analysis was drawn before, during, and after morphine exposure to study the effects on the immune system. Morphine administration resulted in significant suppression of NK cytotoxicity at 2 and 24 hours after beginning intravenous morphine exposure..$^{38}$ Additionally, significant suppression of NKCC was observed at 2 and 24 hours after termination of morphine infusion in the high-dose study group. Gamma-interferon-stimulated NKCC and antibody-dependent cell cytotoxicity were also decreased after 24 hours of intravenous morphine exposure. These results suggest that morphine administration, at doses within the range of analgesic use, can cause marked suppression of components of the human cellular immune system. ${ }^{38}$

The effect of intrathecal morphine on NK cell activity was investigated in patients who underwent a hysterectomy. ${ }^{39}$ This study divided 40 patients into four groups of 10. Three groups received $0.5 \mathrm{mg}$ intrathecal morphine, $0.1 \mathrm{mg}$ intrathecal morphine or $10 \mathrm{mg}$ intravenous morphine, and the control group received inhalational anesthetics alone. Blood samples were drawn at different times to determine blood NK cell activity. ${ }^{39}$ The group that received $0.5 \mathrm{mg}$ intrathecal morphine had lower NK cell activity on a post- 
operative day 1 when compared to baseline level and showed recovery on postoperative day 2 . The control group and the groups administered $0.1 \mathrm{mg}$ intrathecal morphine, and intravenous morphine showed no significant change in NK cell activities. ${ }^{39}$ These results are consistent with the study by Yokota et al. ${ }^{40}$ in which NK cell activity was shown to decrease on a postoperative day 1 in groups receiving $0.5 \mathrm{mg}$ intrathecal morphine. Additionally, this study concluded that the combination of morphine and noradrenaline prolonged the suppression of NK cell activity. ${ }^{40}$

\section{Tramadol}

Tramadol is a centrally acting analgesic with a double mechanism of action. It binds with low affinity to $\mu$-opioid receptors and inhibits serotonin and noradrenaline uptake with the activation of central monoaminergic pathways. This drug has been studied in animals and humans with consistent results.,

The effect of tramadol on immune response has been evaluated in rats, evidencing that, unlike morphine, tramadol does not suppress immune cell function. Instead, it has been reported to enhance NK activity, lymphocyte proliferation, and IL-2 production. ${ }^{41}$

The phagocytic capacity of polymorphonuclear cells and monocytes sampled from healthy volunteers was evaluated in vitro, in which morphine and tramadol were compared. ${ }^{42}$ It was shown that tramadol did not affect the percentage of cells with phagocytic activity nor the phagocytic index.

On the contrary, morphine decreased the phagocytic capacity of polymorphonuclear cells and monocytes in a dose-dependent fashion. ${ }^{42}$

A study conducted by Sacerdote et al. ${ }^{7}$ assessed the immune consequences of morphine and tramadol for the management of postoperative pain in 30 patients undergoing abdominal surgery for uterine carcinoma. The authors observed faster and more complete recovery of immune function with tramadol compared to morphine.

Comparable results were reported in a prospective, randomized clinical trial designed to investigate the effect of patient-controlled analgesia administration of morphine, tramadol and the combination of tramadol and lornoxicam on subtypes of $\mathrm{T}$ cells, NK cells and activated T cells in patients planned to undergo elective surgery for gastric cancer..$^{43}$ In the morphine group, none of the cellular subtypes had returned to their basal values within 48 hours of sur- gery, which contrasted with what was observed in the tramadol group. After 72 hours, cellular subtypes of NK cells and activated T cells remained at low levels in the morphine-exposed group.$^{43}$

\section{DISCUSSION}

Clinical relevance

Studies with human subjects come with ethical considerations that restrict their use, particularly controlled, randomized clinical trials using placebo medications in acute pain and intensive care areas to produce high-quality evidence. Therefore, the conclusions in these settings are limited. ${ }^{23}$ Opioids are undoubtedly the fundamental component of analgesia in general anesthesia, as they control the response to surgical stress and alleviate the acute postoperative pain associated with major surgery. ${ }^{2}$

The potential immunosuppressive effect of opioids during the perioperative period has been documented; however, it is known that inadequate pain control and the increased autonomic and metabolic response associated with surgical trauma in major surgery increases perioperative morbidity. ${ }^{20}$ This immunosuppressive effect in surgery is associated with both inhaled and intravenous anesthetics. They also have a variable effect on cytokines depending on the agent used for general anesthesia ${ }^{44}$ which further limits interpretation of the results of current studies.

Opioids have a different mechanism of action related to the immune system, and differences in immunosuppressive potential exist between subgroups of opioids. ${ }^{45}$ In addition, there is evidence that the immunosuppressive effect of opioids is independent of their antinociceptive effect; therefore, it is essential to individually evaluate the effect of each opioid on the immune system. Opioids with low receptor affinity such as tramadol have been demonstrated to have a lower immunosuppressive potential in animal and human studies. This may be clinically relevant when choosing an analgesic for immunocompromised patients. ${ }^{42}$ Experimental studies have shown that opioid treatment or abrupt interruption of treatment leads to immunosuppression or an increased incidence of infections. However, the results of clinical trials are not conclusive. There is not sufficient evidence to conclude that opioids generate a clinically significant increase in the incidence of perioperative infections. ${ }^{23}$ Further- 
more, the clinical relevance of these trials remains unknown. Currently, it is not possible to provide clear guidelines for how to handle different scenarios in clinical practice. ${ }^{46,47}$

Every type of drug has a different effect on the immune system. Thus, future studies should characterize opioids and their effect on specific subpopulations, including immunocompromised and critically ill patients. ${ }^{46}$ However, while there is a need to determine the underlying mechanisms by which opioids modulate the immune system, in addition to improving the methodological design of further studies, the current literature suggests that the potential effects of treatments with opioids should be considered, especially in susceptible patients. ${ }^{3}$

\section{CONCLUSIONS}

Opioids are essential drugs to control the response to surgical stress during both anesthesia and acute postoperative pain treatment. Despite their positive effects, they may also enhance the immunosuppression generated by surgery and pain.

The intraoperative use of high doses of fentanyl may prolong NK cell cytotoxicity suppression associated with surgery, in addition to disrupting proinflammatory cytokine production during the postoperative period. However, there is no consensus in the current literature.
The suppressive effect of morphine on NK cell activity during the postoperative period has been documented for both intravenous and intrathecal administration in humans, and there is a dose-effect relationship.

Remifentanil has been associated with an increased incidence of surgical site infection in patients undergoing colorectal surgery. Furthermore, it has been shown to alter the number of leukocytes and neutrophils transiently.

Opioids have different effects on the immune system regardless of their antinociceptive potential. Opioids with lower receptor activity, such as tramadol, have been shown to have a reduced immunosuppressive effect, with consistent results in both animals and humans.

Most in vitro and in vivo studies that assessed the effect of opioids including fentanyl, remifentanil, and morphine during the perioperative period have shown that these drugs accentuate the immunosuppression associated with surgical stress in a dose-dependent fashion. These results should be interpreted with caution due to the different methods used to measure the functionality of the immune system, the variability of the dose used and the small number of participants in the studies available.

The authors gratefully acknowledge the assistance of Alejandro Moyano for his assistance with figures.

\section{RESUMO}

INTRODUÇÃO: Os opioides interagem com ambos os sistemas imunes, inato e adaptativo, através de efeitos diretos sobre os receptores dos opioides localizados nas células imunes. As pesquisas neste assunto têm fornecido evidência da influência dos opioides sobre a resposta imune associada ao estresse cirúrgico.

Os efeitos imunológicos dos opioides estão sendo pesquisados na atualidade, principalmente se eles determinam o resultado da cirurgia ou doença consequente devido a fatos importantes como infecção ou progressão do câncer.

Essa revisão tem como alvo ver antecedentes em pesquisa relativa à influência dos receptores dos opioides no sistema imunológico, o efeito imunossupressor associado com opioides maiores durante o período peri-operatório e sua importância clínica.

O objectivo da pesquisa foi revisar os efeitos dos opioides no sistema imunológico.

MÉTODOS: Uma estrategia de procura foi dirigida na mídia PubMed, e no cadastro de Embase e The Cochrane, usando os termos "imunosuppressão", "sistema imunológico", "procedimentos cirúrgicos", "analgésicos", "opioides" e "cuidado peri-operatório".

RESULTADOS: O efeito imunosuppressor dos opioides foi identificado há mais de 30 anos. Os efeitos imunosupressores incluem sinalização e ação diretamente através das células imunes, mesmo com os linfócitos B e T, células NK, monócitos e macrófagos, também como ativando as vias de corrente do eixo hipotálamo- hipófise- adrenal (HPA) levando à produção de glucocorticoides imunossupresores no sistema nervoso periférico e simpático.

PALAVRAS CHAVE: Imunossupressão. Sistema imunitário. Procedimentos cirúrgicos operatórios. Analgésicos. Analgésicos opioides.

\section{REFERENCES}

1. Fedesarrollo y Fundación Saldarriaga Concha. Misión Colombia Envejece: cifras, retos y recomendaciones. Bogotá: Editorial Fundación Saldarriaga Concha; 2015. 706p.
2. Greco A, Faris |, DeLapp V, Hoffman |. Multimodal pain management and effect on opioid use postoperatively in non-ICU patients. Crit Care Med. 2018;46(1):775. 
3. Sacerdote P, Franchi S, Panerai AE. Non-analgesic effects of opioids: mechanisms and potential clinical relevance of opioid-induced immunodepression. Curr Pharm Des. 2012;18(37):6034-42.

4. Cata JP, Bauer M, Sokari T, Ramirez MF, Mason D, Plautz G, et al. Effects of surgery, general anesthesia, and perioperative epidural analgesia on the immune function of patients with non-small cell lung cancer. J Clin Anesth. 2013;25(4):255-62

5. Ninković J, Roy S. Role of the mu-opioid receptor in opioid modulation of immune function. Amino Acids. 2013;45(1):9-24.

6. Sacerdote P. Opioids and the immune system. Palliat Med. 2006;20(Supp 1): S9-15.

7. Sacerdote P, Bianchi M, Gaspani L, Manfredi B, Maucione A, Terno G, et al. The effects of tramadol and morphine on immune responses and pain after surgery in cancer patients. Anesth Analg. 2000;90(6):1411-4.

8. Beilin B, Shavit Y, Hart J, Mordashov B, Cohn S, Notti I, et al. Effects of anesthesia based on large versus small doses of fentanyl on natural killer cell cytotoxicity in the perioperative period. Anesth Analg. 1996;82(3):492-7.

9. Inagi T, Suzuki M, Osumi M, Bito H. Remifentanil-based anesthesia increases the incidence of postoperative surgical site infection. J Hosp Infect. 2015;89(1):61-8.

10. Pasternak GW, Pan YX. Mu opioids and their receptors: evolution of a concept. Pharmacol Rev. 2013;65(4):1257-317.

11. Wybran J, Appelboom T, Famaey JP, Govaerts A. Suggestive evidence for receptors for morphine and methionine-enkephalin on normal human blood T lymphocytes. J Immunol. 1979;123(3):1068-70.

12. Rittner HL, Brack A, Stein C. Pain and the immune system. Br J Anaesth. 2008;101(1):40-4.

13. Labuz D, Berger S, Mousa SA, Zöllner C, Rittner HL, Shaqura MA, et al. Peripheral antinociceptive effects of exogenous and immune cell-derived endomorphins in prolonged inflammatory pain. I Neurosci. 2006;26(16):4350-8

14. Sacerdote P, Limiroli E, Gaspani L. Experimental evidence for immunomodulatory effects of opioids. Adv Exp Med Biol. 2003;521:106-16.

15. Panerai $A E$, Sacerdote P. Beta-endorphin in the immune system: a role at last? Immunol Today. 1997;18(7):317-9.

16. Vallejo R, de Leon-Casasola O, Benyamin R. Opioid therapy and immunosuppression: a review. Am J Ther. 2004;11(5):354-65.

17. Eisenstein TK, Hilburger ME. Opioid modulation of immune responses: effects on phagocyte and lymphoid cell populations. J Neuroimmunol. 1998;83(1-2):36-44.

18. Flores $L R$, Hernandez MC, Bayer BM. Acute immunosuppressive effects of morphine: lack of involvement of pituitary and adrenal factors. | Pharmacol Exp Ther. 1994;268(3):1129-34.

19. Desborough JP. The stress response to trauma and surgery. $\mathrm{Br} \mid$ Anaesth 2000;85(1):109-17.

20. Alsina E, Matute E, Ruiz-Huerta AD, Gilsanz F. The effects of sevoflurane or remifentanil on the stress response to surgical stimulus. Curr Pharm Des. 2014;20(34):5449-68.

21. Pathan $\mathrm{H}$, Williams J. Basic opioid pharmacology: an update. $\mathrm{Br}$ J Pain 2012;6(1):11-6

22. Jamison RN, Mao J. Opioid Analgesics. Mayo Clin Proc. 2015;90(7):957-68.

23. Brack A, Rittner HL, Stein C. Immunosuppressive effects of opioids: clinical relevance. | Neuroimmune Pharmacol. 2011;6(4):490-502.

24. Calvey TN, Williams NE. Principles and practice of pharmacology for anesthetists [Internet]. Oxford: Blackwell Publishing; 2009. [cited 2018 Feb 19]. Available from: http://doi.wiley.com/10.1002/9781405194853

25. Imani F, Motavaf M, Safari S, Alavian SM. The therapeutic use of analgesics in patients with liver cirrhosis: a literature review and evidence-based recommendations. Hepat Mon. 2014;14(10):e23539.
26. Dwyer IP, layasekera C Nicoll A. Analgesia for the cirrhotic patient: a literature review and recommendations. I Gastroenterol Hepatol. 2014;29(7):1356-60

27. Yardeni IZ, Beilin B, Mayburd E, Alcalay Y, Bessler H. Relationship between fentanyl dosage and immune function in the postoperative period. I Opioid Manag. 2008;4(1):27-33.

28. Yeager MP, Procopio MA, DeLeo JA, Arruda JL, Hildebrandt L, Howell AL. Intravenous fentanyl increases natural killer cell cytotoxicity and circulating CD16(+) lymphocytes in humans. Anesth Analg. 2002;94(1):94-9.

29. Jacobs R, Karst M, Scheinichen D, Bevilacqua C, Schneider U, Heine J, et al. Effects of fentanyl on cellular immune functions in man. Int I Immunopharmacol. 1999;21(7):445-54.

30. Wilhelm W, Kreuer $\mathrm{S}$. The place for short-acting opioids : special emphasis on remifentanil. Crit Care. 2008;12(Suppl 3): S5.

31. Mandel JE. Considerations for the use of short-acting opioids in general anesthesia. J Clin Anesth. 2014;26(1 Suppl): S1-7.

32. Scott LJ, Perry CM. Remifentanil: a review of its use during the induction and maintenance of general anaesthesia. Drugs. 2005;65(13):1793-823.

33. Scott LJ, Perry CM. Spotlight on remifentanil for general anaesthesia. CNS Drugs. 2005;19(12):1069-74

34. Sacerdote P, Gaspani L, Rossoni G, Panerai AE, Bianchi M. Effect of the opioid remifentanil on cellular immune response in the rat. 2001;1(4):713-9.

35. Cronin Al, Aucutt-Walter NM, Budinetz T, Bonafide CP, DiVittore NA Gordin V, et al. Low-dose remifentanil infusion does not impair natural killer cell function in healthy volunteers. 2003;91(6):805-9.

36. Hyejin J, Mei L, Seongheon L, Cheolwon J, Seokjai K, Hongbeom B, et al. Remifentanil attenuates human neutrophils activation induced by lipopolysaccharide. Immunopharmacol Immunotoxicol. 2013;35(2):264-71.

37. Hofbauer R, Frass M, Gmeiner B, Sandor N, Schumann R, Wagner O, et al. Effects of remifentanil on neutrophil adhesion, transmigration, and intercellular adhesion molecule expression. Acta Anaesthesiol Scand. 2000;44(10):1232-7.

38. Yeager MP, Colacchio TA, Yu CT, Hildebrandt L, Howell AL, Weiss I, et al. Anesthesiology. 1995;83(3):500-8.

39. Yokota T, Uehara K, Nomoto Y. Intrathecal morphine suppresses NK cell activity following abdominal surgery. Can J Anaesth. 2000;47(4):303-8.

40. Yokota T, Uehara K, Nomoto Y. Addition of noradrenaline to intrathecal morphine augments the postoperative suppression of natural killer cell activity. | Anesth. 2004;18(3):190-5.

41. Sacerdote P, Bianchi M, Manfredi B, Panerai AE. Effects of tramadol on immune responses and nociceptive thresholds in mice. Pain. 1997;72(3):32530.

42. Beilin B, Grinevich G, Yardeni IZ, Bessler H. Tramadol does not impair the phagocytic capacity of human peripheral blood cells. Can | Anaesth. 2005;52(10):1035-9

43. Wang ZY, Wang CQ, Yang IJ, Sun J, Huang YH, Tang QF, et al. Which has the least immunity depression during postoperative analgesia: morphine, tramadol, or tramadol with lornoxicam? Clin Chim Acta. 2006;369(1):40-

44. Iwasaki M, Edmondson M, Sakamoto A, Ma D. Anesthesia, surgical stress, and "long-term" outcomes. Acta Anaesthesiol Taiwan. 2015;53(3):99-104.

45. Martucci C, Panerai AE, Sacerdote P. Chronic fentanyl or buprenorphine infusion in the mouse: similar analgesic profile but different effects on immune responses. Pain. 2004;110(1-2):385-92.

46. Garcia JB, Cardoso MG, Dos-Santos MC. Opioids and the immune system: clinical relevance. Rev Bras Anestesiol. 2012;62(5):709-18.

47. Boland JW, McWilliams K, Ahmedzai SH, Pockley AG. Effects of opioids on immunologic parameters that are relevant to anti-tumour immune potential in patients with cancer: a systematic literature review. Br J Cancer. 2014;111(5):866-73. 